\title{
Deworming efficacy of Albizia anthelmintica in Uganda: preliminary findings
}

\author{
Jeanne T. Gradé ${ }^{1,2, *}$, John R. S. Tabuti ${ }^{3}$, Patrick Van Damme ${ }^{2}$ and Bennett L. Arble ${ }^{4}$ \\ ${ }^{1}$ Christian Veterinary Mission, PO Box 2203 Jinja, Uganda and Karamoja Christian Ethnoveterinary Program, PO Box 22 Moroto, Uganda, \\ ${ }^{2}$ Laboratory of Tropical and Subtropical Agronomy and Ethnobotany, Faculty of Bioscience Engineering, 653 Coupure links (Ghent University), \\ B-9000 Gent, Belgium, ${ }^{3}$ Department of Botany, Makerere University, PO Box 7062 Kampala, Uganda and ${ }^{4}$ School of Veterinary Medicine, \\ University of Wisconsin, 2015 Linden Drive Madison, WI 53706, U.S.A.
}

\begin{abstract}
This study was conducted to evaluate the anthelmintic effectiveness of Albizia anthelmintica, as a first step in investigating the hypothesis that livestock self-medicate. In July 2006, an observational study was conducted with 56 young female lambs, to validate $A$. anthelmintica efficacy. Faecal egg per gram for Coccidia, Strongyle-type, Monezia, Strongyloides and Dicrocoelia eggs were counted and analysed. Results indicate that $A$. anthelmintica is effective in controlling infection with a variety of internal parasites in lambs, Monezia was the most sensitive. Furthermore, treatment of Strongyle-type worms requires a biweekly dose of $A$. anthelmintica as an effective deworming protocol.
\end{abstract}

Key words: anthelmintic, ethnoveterinary, Karamoja, livestock, self-medication

\section{Introduction}

African traditional healers learn from experience, one another (Tabuti, Dhillion \& Lye, 2003), and also from observing the behaviour of animals (Huffman, 2003). There are numerous accounts of self-medication in the great apes (e.g. Wrangham \& Nishida, 1983; Huffman, 1997, 2003; Krief, Hladlik \& Haxaire, 2005). Self-medication has not, however, been reported in livestock. In 2000, during a participatory deworming field trial in Uganda, we observed goats' browsing behaviours suggestive of self-medication. This observation was strengthened by a shepherd who claimed to have observed goats grazing on ekapangiteng (Albizia anthelmintica Brong.), followed by gross expulsion of worms in the goats' faeces. This observation was

*Correspondence: E-mail: jeangrade@yahoo.com

All authors declare no conflicts of interest intriguing because animals generally avoid browsing the bitter leaves of $A$. anthelmintica. East Africans widely use A. anthelmintica to control helminth parasites in human and animal medicine in Sudan (Koko, Galal \& Khalid, 2000), Ethiopia (Desta, 1995) and Tanzania (Minja, 1994).

The objective of this study was to evaluate the anthelmintic effectiveness of $A$. anthelmintica, as a first step in investigating the hypothesis that livestock self-medicate. This research forms part of a larger ethnoveterinary study of the pharmacopoeia of Karamojong pastoralists.

\section{Methods}

Study site

Karamoja is located in the northeastern corner of Uganda, bordering Kenya and Sudan. It is characterized by a relatively flat savannah with some hills and mountains rising up to $3800 \mathrm{~m}$. The semi-arid environment receives 350$750 \mathrm{~mm}$ rain per annum. The original vegetation was characterized as dry Acacia-Combretum-Terminalia (Langdale-Brown, 1959). The herb layer is composed of Hyparrhenia, Setaria, Themeda, Cymbopogon and Sporobolus grass species. The short vegetation shows evidence of heavy grazing, in stark contrast with the neighbouring districts, where the people are less dependent upon livestock for survival.

The Nilo-Hamitic Karamojong numbering about 900,000 are transhumant agro-pastoralists widely dependent upon their cattle, supplemented by subsistence farming (UBOS, 2002). Their semi-nomadic lifestyle is dictated by the grazing seasons of their livestock. Karamojong live in circular homesteads (manyattas) characterized by thick, thorny, concentric fences that encompass 2-5 acres and enclose ten to 30 mud-thatched huts. Women and 
children live in the manyatta year-round. During the dry season, the men and youth herd livestock to migratory cattle areas, where they sleep in the open or in low grass huts. External influences are minimal and 99\% of the population rely exclusively on indigenous knowledge, medicines, and practices for themselves and their livestock.

\section{Methods}

An observational study was conducted in July 2006 to validate anthelmintic efficacy of $A$. anthelmintica. Fifty-six young female lambs were locally purchased from three Karamojong subcounties. Baseline data were collected to chart out health variables and monitor changes during the field trial on each individual animal. These included: physical examination, live body weight, packed cell volume (PCV, an indicator of anaemia) and total protein (TP, a hydration status indicator) of blood samples. The numbers of parasite eggs per gram of feaces (EPG) were determined by the modified McMaster's technique (Campbell et al., 1978), for five different parasites (Strongyle-types, Monezia, Strongyloides, Coccidia and Dicrocoelia) for each sample. Based on the baseline data, 30 lambs were distributed into three groups of ten lambs each. Groups were created to ensure an even distribution of nine factors, including total EPG and district of origin.

The three groups were: negative control (no treatment), two test groups, one with an allopathic dewormer (levamisole, Wormicid $^{\circledR}$, Cosmos Limited, Nairobi, Kenya) at label dose, and another one using shade-dried A. anthelmintica bark, which had been prepared by crushing to make a powder and packed into standard gelatin capsules at the traditional healers' recommended dose of $0.8 \mathrm{~g}$. Treatments were given orally on day 0 .
In determination of the optimal dosing schedule for $A$. anthelmintica, half of the lambs in each treatment group were re-treated on day 14 . Blood was collected for determination of PCVs and TPs on days 14 and 35. Body weight was repeated on day 35 .

Coccidia, Strongyle-type, Monezia, Strongyloides and Dicrocoelia eggs were identified. This preliminary study focuses on the first three parasite types, as they are the most clinically important. Anthelmintic efficacy was estimated as the percent faecal egg count reduction (FECR) using the following equation after Coles et al. (1992). $T$ and $C$ represent mean EPGs of the treated and control groups; subscript 1 refers to the EPG on day 0, and subscript $n$ refers to EPG counts in a given week:

$$
\mathrm{FECR}=\left(1-\left(\frac{T_{n}}{T_{1}} \times \frac{C_{1}}{C_{n}}\right)\right) \times 100 .
$$

The FECR represents the per cent reduction change in the average EPG of animals in the treatment group, compared to the change in the average EPG of negative control animals. It is directly correlated to the efficacy of the treatment: a more effective medication correlates with a more highly positive FECR, up to a maximum of $100 \%$. A negative FECR indicates that the animals in the treatment group showed either a smaller decrease, or a greater increase, in the average number of parasite eggs shed, than did animals in the negative control group.

\section{Results and discussion}

The FECR was positive for each of the parasite types, indicating efficacy of $A$. anthelmintica against all parasites examined in this study. As shown in Table 1, the FECR of Strongyle-type eggs, the most clinically important group,

Table 1 Efficacy of herbal medicine made from Albizia anthelmintica compared to allopathic (levamisole)

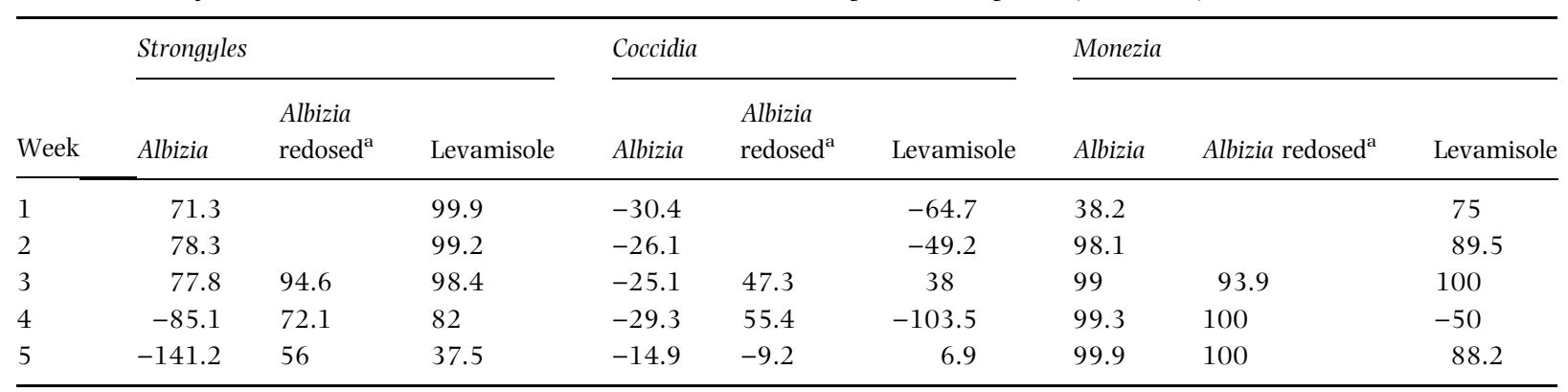

The per cent faecal egg count reductions (FECR) of three different parasites in female lambs are shown.

aThese columns refer to data from the half of the animals in each group which were retreated on day 14. 
ranged from $71 \%$ to $78 \%$ for the first 3 weeks. Animals in the re-dosed group had an average FECR of almost $95 \%$ on week 3 , tapering to $72 \%$ and $56 \%$ on weeks 4 and 5 respectively.

The lambs' Coccidia level did not respond to herbal treatment by $A$. anthelmintica (average FECRs $-15 \%$ to $-30 \%)$; but re-dosed animals fared better, with averages of $47 \%$ and 55\% in weeks 3 and 4 . The FECR of Monezia eggs was consistently over $94 \%$ after the first week.

No differences were observed between groups in PCV, TP or live weight gain. This implies that the differences in worm-load had little effect on weight gain or anaemia; however data are still being collected.

Results of this study indicate that A. anthelmintica is effective in controlling infection with a variety of internal parasites in lambs. Furthermore, treatment of Strongyletype worms requires a biweekly dose of $A$. anthelmintica as an effective deworming protocol. This study continues to further standardize the dosage according to body weight. Efficacy of $A$. anthelmintica will also be examined in other livestock species.

\section{Acknowledgements}

We thank the Karamojong Traditional Livestock Healers for their wisdom and animal handling.

\section{References}

Campbell, N.J., Hall, C.A., Kelly, J.D. \& Martin, I.C.A. (1978) The anthelmintic efficacy of non-benzimidazole anthelmintics against benzimidazole resistant strains of Haemonchus contortus and Trichostrongylus colubriformis in sheep. Aust. Vet. J. 54, 23-25.
Coles, G.C., Bauer, C., Borgsteede, F.H.M., Gerts, S., Klei, T.R., TAYLOR, M.A. \& WALLER, P.J. (1992) World association for the advancement of veterinary parasitology (WAAVP) methods for detection of anthelmintic resistance in nematodes of veterinary importance. Vet. Parasitol. 44, 35-44.

Desta, B. (1995) Ethiopian traditional herbal drugs. Part I studies on the toxicity and therapeutic activity of local taenicidal medications. J. Ethnopharmacol. 45, 27-33.

Huffman, M.A. (1997) Current evidence for self-medication in primates: a multidisciplinary perspective. Yearb. Phys. Anthropol. 39. 60-199.

Huffman, M.A. (2003) Animal self-medication and ethno-medicine: exploration and exploitation of the medicinal properties of plants. Proc. Nutr. Soc. 62, 371-381.

KoKo, W.S., Galal, M. \& Khalid, H.S. (2000) Fasciolocidal efficacy of Albizia anthelminitca and Balanites aegyptiaca compared with albendazole. J. Ethnopharmacol. 71, 247-252.

Krief, S., HLADLIK, C.M. \& HaXaire, C. (2005) Ethnomedicinal and bioactive properties of plants ingested by wild chimpanzees in Uganda. J. Ethnopharmacol. 101, 1-15.

Langdale-Brown, I. (1959) The vegetation of the Eastern Province of Uganda: Department of Agriculture. Kawanda Research Station. Memoirs of Research Division, Ser. 2: Vegetation, No. 1. Uganda Government.

MinJA, M.M.J. (1994) Medicinal plants used in the promotion of animal health in Tanzania. Rev. Sci. Tech. VOIE 13, 905-925.

TAButi, J.R.S., Dhiluion, S.S. \& Lye, K.A. (2003) Traditional medicine in Bulamogi county, Uganda: its practitioners, users and viability. J. Ethnopharmacol. 85, 119-129.

Uganda Bureau of Statistics (UBOS) (2002) Population Census 2002. UBOS, Kampala, Uganda.

Wrangham, R.W. \& NishiDA, T. (1983) Aspilia spp. leaves: A puzzle in the feeding behavior of wild chimpanzees. Primates $\mathbf{2 4}$, 276-282.

(Manuscript accepted 20 August 2007) 